\title{
Estratégias utilizadas pela família para cuidar a criança no hospital
}

\author{
Strategies used by families to care for hospitalized child
}

\author{
Estrategias utilizadas por la familia para el cuidado del niño en el hospital
}

Giovana Calcagno Gomes ${ }^{1}$, Fernanda Lucas Lopes de Meirelles Leite ${ }^{2}$ Nathalia Zinn de Souza ${ }^{3}$, Daiani Modernel Xavier ${ }^{4}$, Joana Curcio da Cunha ${ }^{5}$, Daniela Pasini ${ }^{6}$

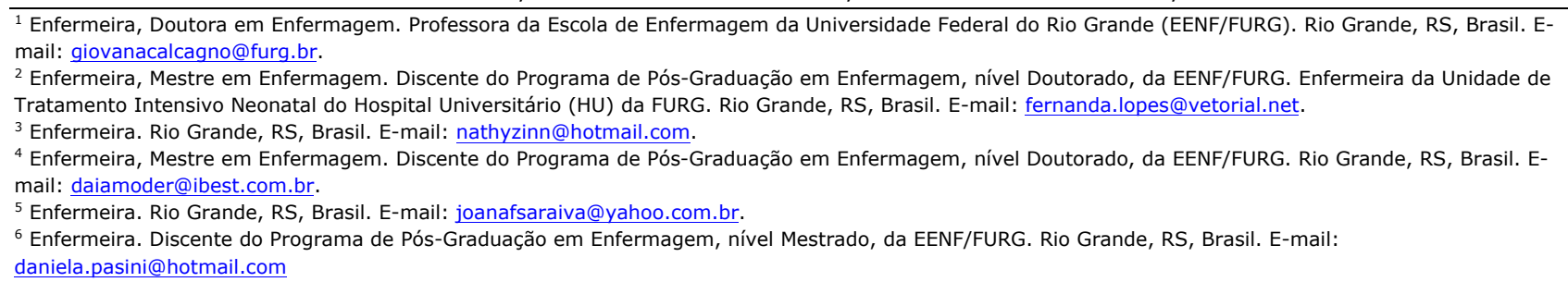
daniela.pasini@hotmail.com

\section{RESUMO}

Objetivou-se conhecer as estratégias utilizadas pela família para cuidar da criança no hospital. O estudo caracterizou-se como de abordagem qualitativa, com referencial metodológico baseado na Teoria Fundamentada nos Dados. Foi desenvolvido em uma unidade de pediatria de um hospital do sul do país. Participaram 18 familiares cuidadores de crianças internadas no primeiro semestre de 2010, divididos em quatro grupos amostrais. A coleta de dados deu-se por entrevistas semiestruturadas. Concomitantemente, procedeu-se à análise aberta e axial dos dados. Os dados mostraram que a família utiliza como estratégias buscar informações acerca do tratamento; reproduzir, no hospital, os cuidados domiciliares; organizar o ambiente do cuidado e familiarizar-se com a tecnologia do cuidado. Concluiu-se que a família, ao implementar estratégias de cuidado à criança no hospital, torna-se copartícipe do seu processo de internação, tornando o ambiente hospitalar humanizado e propiciando à criança um cuidado qualificado, sensível e humano.

Descritores: Criança Hospitalizada; Família; Enfermagem Pediátrica.

\section{ABSTRACT}

This study seeks to investigate the strategies used by families to care for a hospitalized child. A qualitative study with methodological references based on the Grounded Theory. It was conducted in a pediatric ward in a hospital in southern Brazil. Participants comprised 18 families caring for children admitted in the first semester of 2010 divided in four sample groups. Data was collected using semi-structured interviews. Simultaneously, we conducted an open and axial data analysis. The data displayed that families use strategies such as seeking out information about treatment; reproducing home care in the hospital; organizing the care environment and becoming familiar with care technology. We concluded that by implementing care strategies for the hospitalized child, the family becomes co-participants in the hospitalization process, humanizing the hospital environment, and thus providing the child with qualified, sensitive and humane care.

Descriptors: Child, Hospitalized; Family; Pediatric Nursing.

\section{RESUMEN}

Se objetivó conocer las estrategias utilizadas por la familia para cuidar al niño en el hospital. Estudio de abordaje cualitativo con referencial metodológico basado en Teoría Fundamentada en los Datos. Desarrollado en una unidad de pediatría de un hospital del sur del país. Participaron 18 familiares cuidadores de niños internados en el primer semestre de 2010, divididos en cuatro grupos muestrales. Datos recolectados mediante entrevistas semiestructuradas. Conjuntamente, se procedió al análisis abierto y axial de los datos, que mostraron que la familia utiliza como estrategias: buscar informaciones sobre el tratamiento; reproducir en el hospital los cuidados domiciliarios; organizar el ambiente del cuidado y familiarizarse con la tecnología de cuidado. Se concluye en que la familia, al implementar estrategias de cuidado al niño en el hospital, se convierte en copartícipe de su proceso de internación, humanizando al ambiente hospitalario, propiciando un cuidado calificado, sensible y humano para el niño.

Descriptores: Niño Hospitalizado; Familia; Enfermería Pediátrica. 


\section{INTRODUÇÃo}

A hospitalização é percebida como uma situação extremamente e perturbadora na vida de qualquer pessoa e tem contornos especiais quando se trata de um acontecimento com a criança, pois ela pode se configurar como uma experiência potencialmente traumática na medida que a distancia de sua vida cotidiana e do ambiente familiar, onde ela se sente segura e protegida. No hospital, depara-se com um ambiente desconhecido, tendo sua vida familiar afetada, mudando a rotina de toda a família ${ }^{(1)}$.

A família acompanha a criança de perto no hospital compartilhando seu cuidado, vivenciando seu adoecimento, permitindo a compreensão da hospitalização e amparando a criança, oferecendo-lhe conforto. A hospitalização de uma criança suscita na família situação de crise, caracterizada por vários fatores como descontinuidade na satisfação das necessidades biológicas, psicológicas e sociais, e aparecimento do sentimento de culpa e ansiedade ${ }^{(2)}$.

Nesse sentido, o cuidado familiar à criança contribui para o enfrentamento aceitável da hospitalização a tornando capaz de manejar o estresse e as mudanças bruscas que rompem com sua vida diária(3). No hospital, é a família, em especial a mãe, quem permanece em constante interação com a criança. Nesse contexto, apresenta necessidade constante de especializar-se no cuidado da criança. Por ser a principal responsável pelo cuidado busca alternativas para adaptar-se a esta nova situação e organizar-se melhor para cuidar ${ }^{(4)}$.

A necessidade de hospitalização da criança pode ser uma experiência desagradável tanto para ela quanto para a família, pois determina uma mudança na rotina, independente do tempo de internação, exigindo adaptações às mudanças cotidianas. A permanência da criança no ambiente hospitalar não afeta a família apenas pelo fato de existir uma doença, mas também por possuir aspectos de todo o contexto familiar implicados na situação. Isto faz com que os pais necessitem lançar mão de estratégias para o enfrentamento da hospitalização da criança $^{(5)}$.

Uma das estratégias é a busca por informações acerca da doença, do tratamento fornecido à criança no hospital e do possível tempo de internação(5). A aquisição de segurança para cuidar da criança se dá por meio do aprendizado de habilidades técnicas para cuidar, do desenvolvimento de sensibilidade única para identificar as manifestações de melhora ou agravo do estado de saúde da criança e do compartilhamento do cuidado da criança com os profissionais da equipe de saúde ${ }^{(6)}$.
A família é a referência, sendo considerada pela criança como apoio e proteção, pois seu cuidado no hospital possui o componente afetivo necessário neste momento. A presença da família ajuda a criança a aceitar a internação, diminuindo a angústia do abandono em relação aos demais familiares que estão longe e auxilia na formação do vínculo com a equipe de saúde ${ }^{(7)}$.

No entanto, diante desta nova realidade, a criança pode demandar necessidades específicas, sendo importante a aquisição de novas habilidades e competências para garantir um cuidado de qualidade à mesma. Assim, cabe ao enfermeiro a sensibilidade de atenção e percepção destas dificuldades interagindo com a criança e sua família a fim de instrumentalizar o familiar cuidador para os novos referenciais de cuidado que a criança está necessitando. A enfermagem como profissão voltada para o cuidado, além de assistir a criança durante sua internação, precisa cuidar da família que permanece integralmente com ela(7).

Normalmente, a família tem dificuldade para dimensionar as modificações que ocorrerão em seu cotidiano, principalmente quando não conhece muito sobre a doença, os cuidados a serem realizados ou como cuidar e amparar adequadamente a criança doente. Nesse momento, passa a sofrer perante o desconhecido que se estabelece, necessitando de auxílio para adaptar$\mathrm{se}^{(8)}$.

A enfermaria passa a ser o local de permanência da criança e da família no hospital, onde procuram exercer sua singularidade na busca por preservar sua identidade familiar e sua privacidade. Além do ambiente da unidade, ao experienciar a internação hospitalar da criança, a família passa a conviver com a tecnologia ali existente, precisando familiarizar-se com ela. O uso da tecnologia tornou-se, em muitos momentos, algo indispensável, tanto para quem cuida como para quem é cuidado $^{(9)}$.

Ao realizar busca em bases de dados nacionais e internacionais constatou-se uma lacuna de conhecimento acerca da dimensão cuidadora da família à criança no hospital. Utilizando os descritores família e criança hospitalizada observou-se que na PubMed de 171 artigos apenas dois discutiam o papel da família no cuidado à criança. Ambos apontaram o papel protetor e o fornecimento de conforto à criança ${ }^{(10-11)}$.

$\mathrm{Na}$ base de dados Literatura Latino-Americana e do Caribe em Ciências da Saúde (LILACS) de 891 artigos apenas dois enfocam a temática. Um destacou revisa e confere as intervenções dos profissionais com a criança(12). O outro mostrou a família no hospital 
representa segurança para a criança e, além disso, participa da execução de tarefas e cuidados entendidos como semelhantes aos domiciliares como: higiene, banho, alimentação. A realização desses atos pelo familiar acompanhante é um acontecimento já institucionalizado nas unidades de internação pediátrica, sendo rotina aceita por todos de forma acrítica e natural. Muitas ações, antes realizadas pela enfermagem, hoje são entendidas, pelos profissionais, como sendo de competência da família ${ }^{(13)}$.

$\mathrm{Na}$ base de dados Scientific Eletronic Library Online (Scielo) apenas um artigo utilizou os dois descritores concomitantemente, mas não se referiu aos cuidados realizados pela família. $\mathrm{Na}$ base Medical Literature Analysis and Retrieval System On-line (Medline) de 801 artigos dois discutiram a experiência da família, sendo que um destacou o importante papel de vigilância constante que desenvolve no hospital, monitorando continuamente as condições de saúde da criança. Para isso utilizam como estratégia a manutenção de diálogos com os membros da equipe de saúde ${ }^{(14)}$. O segundo discutiu a experiência das mães na participação do cuidado de seus filhos hospitalizados. Referiu que estas estão envolvidas, principalmente, nos cuidados que realizam em casa. Reclamam que são exigidas a realizar cuidados os quais não se sentem preparadas e sentemse ansiosas quando confrontadas com novas formas de cuidado no hospital ${ }^{(15)}$.

Esta busca mostra que apesar da hospitalização infantil ser foco de muitas publicações na área da saúde, pouco se tem discutido acerca da dimensão cuidadora da família no hospital e não se encontraram publicações acerca das estratégias que utilizam para realizar este cuidado. Diante deste cenário, o presente estudo tem como objetivo conhecer as estratégias utilizadas pela família para cuidar a criança no hospital. O conhecimento dessas estratégias torna-se importante para subsidiar a prática da enfermagem junto a essas famílias e crianças.

\section{MÉTODO}

Realizou-se um estudo de abordagem qualitativa com referencial metodológico baseado na Teoria Fundamentada nos Dados (TFD). Essa consiste na coleta, codificação e comparação simultânea e sistemática dos dados, possibilitando explorar o fenômeno investigado gerando teoria que explique e possibilite a compreensão de fenômenos sociais e culturais ${ }^{(16)}$.

Foi desenvolvida na unidade de pediatria de um Hospital universitário do sul do país. Essa unidade é composta de 25 leitos, todos para crianças conveniadas pelo Sistema Único de Saúde (SUS). A população do estudo foi composta por 18 familiares cuidadores de crianças internadas, no primeiro semestre de 2010: 15 foram distribuídos em quatro grupos amostrais, dois formados por cinco familiares, um por três e outro por dois. Três familiares validaram os dados do estudo. Os critérios para a escolha dos participantes foram: ser o principal familiar cuidador da criança no hospital, acompanhar a criança durante sua hospitalização, prestando-Ihe cuidados diretos. Foram excluídos os familiares cuidadores que, no momento da coleta dos dados, não estavam acompanhando a criança no hospital ou não quiseram participar do estudo.

O número de participantes e de grupos amostrais foi determinado pelo processo de amostragem teórica, como recomenda a TFD. Os familiares foram identificados pela letra $\mathrm{F}$ seguida do número da entrevista.

A coleta de dados foi realizada através de entrevistas semiestruturadas. A coleta de dados teve início após a leitura e assinatura do Termo de Consentimento Livre e Esclarecido pelos participantes. Estas foram agendadas com cada familiar, gravadas e transcritas para análise. A partir da coleta, procedeu-se à codificação aberta dos dados na qual foi realizado o exame dos dados linha a linha, recortando as unidades de análise e a codificação axial dos dados, com sua categorização(17).

Em atendimento à Resolução no 196/96 o projeto de pesquisa foi submetido ao Comitê de Ética da Universidade Federal do Rio Grande, recebendo parecer favorável sob n 92/2009.

\section{RESULTADOS}

A análise dos dados identificou cinco categorias: Buscando informações acerca do tratamento fornecido à criança no hospital, Procurando reproduzir no hospital os cuidados domiciliares à criança; Não conseguindo reproduzir no hospital os cuidados domiciliares à criança; Organizando o ambiente do cuidado e Familiarizando-se com a tecnologia do cuidado.

\section{Buscando informações acerca do tratamento fornecido à criança no hospital}

$\mathrm{Na}$ busca por adaptar-se no hospital, o familiar cuidador necessita de informações que o habilitem mais para o cuidado à criança. Muitas são as informações necessárias para que ele possa organizar-se para cuidar. Ele precisa de informações acerca do que vai ser feito com a criança, acerca dos medicamentos, da alimentação e dos exames e procedimentos. 
O querer saber o que vai ser feito com a criança revela que a família tem medo, pergunta tudo; quer saber tudo o que vai acontecer com a criança, procura tirar suas dúvidas com os profissionais da saúde, quer ser a primeira a saber. Estas informações irão acalmar a família fortalecendo-a enquanto cuidadora de seu filho, permitindo que assuma o controle sobre a situação na qual se encontra. Ela quer receber informações que the possibilite cuidar melhor da criança e a impeça de piorar seu quadro clínico.

Qualquer dúvida, eu pergunto. Se eu não entendi, eu pergunto de novo. Eu vou perguntando, perguntando porque sou eu quem está aqui. Eu preciso estar informada de tudo que está acontecendo com ela. Como eu não entendo muito, eu tenho medo do que possa acontece (F1).

Eu pergunto o que posso fazer para melhorar, o que não posso fazer para piorar. O diálogo é essencial porque é o nosso máximo interesse saber tudo sobre nossa filha (F2).

A gente aqui se torna chata. Mas não é porque a gente quer. É porque a gente está muito nervosa. Então, a gente quer saber tudo que está acontecendo para poder se acalmar. Se ele está dormindo muito, eu chamo as gurias. Se ele está chorãozinho eu chamo as gurias (F3).

A família solicita informações acerca dos medicamentos, querendo saber o tipo de medicamento administrado à criança, seus horários e efeitos, de forma a poder controlar melhor a evolução do seu quadro clínico.

Sempre perguntando, querendo saber qual a medicação que ele vai fazer. Eu tenho uma grande preocupação com os remédios, porque ele toma muitos. Quero estar a par de tudo que vai ser feito. Se ele vai dar um remédio a mais, eu quero saber primeiro. Que quantidade que veio, que horários (F15).

Eu pergunto sobre os remédios. Pergunto até entender bem porque sou eu que mando notícias para casa, então, eu tenho que saber tudo (F11).

A família busca informações acerca da alimentação fornecida à criança, pois quer saber o que essa pode ou não comer, os horários das refeições no hospital e as quantidades fornecidas à criança, de forma a evitar a oferta de alimentos inadequados e sua piora.
Eu pergunto sobre a comida porque ela não tem limites e cada um que vem traz uma coisinha. Então, eu preciso saber o que ela pode e o que ela não pode comer. Eu não posso permitir que ela piore. É muito importante ter informações sobre a comida (F8).

Ela internou por causa de alguma coisa que ela comeu e fez mal. Então eu pergunto sobre o que vem, as quantidades, quantas vezes no dia. Eu não posso repetir o mesmo erro de novo (F5).

A busca de informações acerca dos exames e procedimentos revela que, para a família, os resultados dos exames são importantes para esclarecer como a criança está reagindo à terapêutica instituída e como seu quadro clínico está evoluindo. Além disso, saber antecipadamente acerca dos procedimentos a serem realizados na criança possibilita à família prepará-la para estes, de forma que os mesmos não causem trauma na criança.

Perguntando quais são os exames que serão feitos, se vai fazer algum exame a mais (F7).

A minha filha internou para fazer uma tomografia da cabecinha. Então, eu estou aguardando com muita ansiedade o resultado deste exame. Se estiver tudo bem, nós teremos alta. Se não, é um problema, pois pode até ficar com um probleminha na cabeça (Chora). Então, eu preciso saber, ser a primeira a saber (F14).

A minha guria vai fazer um exame na cabeça (eletroencefalograma). Eu preciso saber tudo sobre este exame porque ela já é grandinha, tem medo. Eu preciso saber para explicar melhor para ela. Explicar de um jeito que ela entenda (F12).

\section{Procurando reproduzir no hospital os cuidados domiciliares à criança}

A internação hospitalar pode ser um motivo de maior ou menor trauma para a criança, conforme o modo como esta for vivenciada. A presença da família ao seu lado, no hospital, auxilia a diminuir este trauma. Uma das estratégias utilizadas pela família para ambientar melhor a criança e diminuir seu trauma é procurar reproduzir os cuidados domiciliares como uma forma de manter um elo entre esta e seu domicílio, fortalecendo, assim, a sua identidade.

Na sua busca por reproduzir no hospital os cuidados domiciliares, a família procura tornar a enfermaria parecida com o quarto da criança, trazendo de casa suas cobertas e brinquedos; realizando atividades comuns do domicílio como cantar as mesmas músicas; adaptar sua 
dieta à de casa; fazendo com que os familiares venham visitar a criança, entre outras estratégias.

Aqui no quarto, eu procurei reproduzir um pouquinho do quarto dele. Trouxe as cobertas dele, os brinquedos dele, o copinho dele, os joguinhos. (F3).

Eu procuro fazer tudo igual para ele não estranhar. Eu converso com ele, eu fico perguntando pela sobrinha dele, pelo nome dela. Para ele não se esquecer dela, da tia. Ele fica me escutando e ri. (F4).

No meu cuidado não tem diferença. Em casa é 24 horas para ele e aqui, também. Procuro fazer tudo igual. (F15). A alimentação está sendo a mesma. A gente conversou com a nutricionista e ela está recebendo direitinho igual em casa. A atenção que ela recebe da gente, também, é a mesma (F12).

\section{Não conseguindo reproduzir no hospital os cuidados domiciliares à criança}

Ao tentar adaptar-se ao hospital e reproduzir os cuidados domiciliares à criança, a família encontra algumas dificuldades. Percebe que o ambiente hospitalar, com normas, regras, profissionais, exames e procedimentos é muito diferente que a sua casa. Neste contexto, a família apresenta dificuldade em reproduzir até mesmo alguns cuidados simples como o banho e a alimentação da criança, necessitando aprender um novo modo de cuidar para dar conta das novas necessidades de cuidado da criança.

A criança, no hospital, torna-se temerosa e apresenta alterações variadas no comportamento, exigindo da família carinho e paciência. Verificou-se que, tendo em vista a doença da criança, sua família apresenta dificuldade em impor-Ihe limites no hospital.

Os cuidados com ele são bem diferentes do que em casa, porque para dar banho tem que cuidar o soro, a mão. Para dar comida ele está enjoadinho, chorãozinho. Colocar a roupa é difícil por causa do soro. A gente tenta fazer igual, mas é diferente. Tem que ter o dobro de paciência, o dobro de carinho (F3).

Ela aqui colocou uma sonda para se alimentar melhor porque ela se engasgava muito em casa com a comida. $E$ aí eu tive que aprender a dar comida desta forma, pela sonda e com uma seringa (F15).

A família não apresenta, no hospital, a mesma liberdade para cuidar que em casa, podendo sentir-se controlada pela equipe de saúde.
Aqui no hospital tem os médicos, as enfermeiras, todo mundo que eu não tenho em casa. Eles é quem me ajudam a cuidar aqui. Então, para cuidar a gente tem que se combinar (F10).

o cuidado aqui é muito diferente do de casa. Aqui é assim, tudo com horinha marcada. Em casa não. Aqui é hora de almoço tem que comer. É hora dos banhos tem que tomar. Em casa, tem mais liberdade. É tudo no nosso ritmo. É conforme o que se tem para fazer naquele dia (F8).

\section{Organizando o ambiente do cuidado}

No hospital, o espaço familiar para o cuidado tornase limitado, muitas vezes, a uma cama e uma cadeira. Além disso, a família, na maioria das vezes, precisa dividir este espaço de cuidado com outras famílias. Para melhor cuidar, a família procura organizar o ambiente do cuidado ocupando o espaço da enfermaria com as suas coisas; de forma a propiciar maior conforto para a criança. Ao organizar seu ambiente de cuidado, a família procura preservar sua identidade, exercendo sua singularidade de ser família, apesar de conviver, neste momento, com a pluralidade da enfermaria coletiva:

Organizo este canto aqui do meu jeito. Coloco as minhas coisas ali. Tem que toda hora estar arrumando para não ficar bagunçado (F13)

Este canto aqui é o nosso. Aqui que a gente come, que a gente dorme, que a gente recebe visitas. Eu arrumo o nosso bidê do nosso jeito. Bem alegre, com tudo que é dela pra ela enxergar e brincar facilmente (F8).

Eu tento não deixar ele perceber muito a diferença entre o hospital e lá em casa. É claro, ele percebe, mas em relação ao conforto eu trago a cadeira de rodas dele para cá. Eu trago um brinquedo, alguma coisa que ele goste eu trago para cá. Fiz um mural de fotografias na parede, coloquei uns balões bem coloridos na volta para deixar o ambiente melhor (F10).

A família preocupa-se com a limpeza da enfermaria e colabora realizando-a ou conservando a limpeza feita pelos profissionais do Serviço de Higienização:

A gente procura manter o chão limpo, as camas arrumadas, o bidê arrumado. Cuidado é com a cama arrumada, o quarto arrumado, o quarto limpo. Isso é cuidado. A gente organiza o quarto, procurando fazer o máximo possível para ela ficar limpa. Manter a higiene, não deixar os alimentos espalhados, não deixar as coisas espalhadas que nem a gente faz em casa. A gente, aqui 
fica que nem a diarista, limpando tudo o tempo todo (F2).

Aqui eu limpo o chão, eu varro. Eu acho que não pode ter sujeira. Se vai ser tratado na sujeira não está bem tratado (F10).

As famílias que coabitam a mesma enfermaria traçam conjuntamente regras de boa convivência, permitindo que cada uma organize o cuidado à sua criança do seu jeito. Propiciam que cada família tenha o seu espaço delimitado, mesmo que pequeno, de forma a nele realizarem suas interações. Este espaço organizado do jeito da família e por ela torna-se a sua casa dentro do hospital, local onde ela come, conversa, recebe visitas, interage com outras pessoas e vivencia a experiência da internação junto com a criança.

Ainda não levei para passear porque ainda não têm condições. A gente tenta familiarizar a criança no hospital para que ela se sinta assim o máximo como se fosse em casa. Traz a cobertinha, procuro contar as mesmas coisas que a gente conta em casa, as mesmas músicas. Procuramos ficar toda a família reunida na volta dela como está aqui: o pai, a mãe e a irmã. Procuramos trazer para cá, neste espaço nosso aqui, o ambiente que ela tem em casa. Através de carinho, de música, de tudo que a gente costuma fazer com ela em casa. A gente trouxe para cá com mais carinho ainda (F2).

Ela (a colega de quarto) já trouxe, eu acho, que a casa aqui para dentro do quarto. Até o carrinho do guri ela trouxe, mas coloca tudo ali, no canto dela. Eu, também, não fico atrás. Olha tudo que eu trouxe. (ri). Mas a gente combina. Ninguém invade o espaço do outro. Ė só para que o nosso espaço tenha mesmo a nossa cara. Eu acho que ameniza um pouco esta coisa de hospital (F3).

\section{Familiarizando-se com a tecnologia do cuidado}

$\mathrm{Na}$ sua busca por adaptar-se ao hospital, para melhor cuidar da criança, a família passa a conviver com a tecnologia do cuidado ali existente. A família cuida, mas não o faz sozinha. Interage diariamente com os membros da equipe de saúde em suas relações de cuidado. Nestas interações, as famílias conhecem uma forma diferente da sua de cuidar e, passam a realizar na criança alguns destes cuidados utilizando a tecnologia disponível no hospital com a qual precisam familiarizarse, como manipular sondas para aspiração e alimentação; usar luvas de borracha; cuidar da criança com soro e acompanhar os profissionais, durante a realização dos procedimentos. o cuidado aqui é melhor porque em casa eu não tenho aspirador, nebulizador. Dou leite para ela pela boca e ela se engasga muito e faz as pneumonias. Aqui, é por sonda e é melhor (F6).

Eu ajudo na nebulização, cuido do sorinho para não terminar (F11).

Eu uso a sonda para aspirar, eu uso a luva de borracha. Eu tenho um aspirador aqui só para ele. Eu me organizei toda para cuidar. Se for necessário, eu mesma aspiro, sei fazer nebulização, sei fazer a fisioterapia. Eu aprendi tudo aqui no hospital, de tanto internar. Como eu faço aqui eu faço em casa. (F10).

Ele precisou fazer uma flebotomia. Não tinha mais condições, as veias estavam todas estouradas. Então, eu decidi que o melhor era ajudar elas a segurar ele para o médico fazer. Foi difícil, mas eu aguentei até o fim. (F4).

A necessidade de um suporte tecnológico para o cuidado à criança pode causar impacto e sofrimento para a família, uma vez que ela necessitará adquirir habilidades para lidar com esta tecnologia e (re)organizar-se para cuidar, tendo que, muitas vezes, superar barreiras emocionais e intelectuais difíceis.

\section{DISCUSSÃo}

A partir do momento em que a família recebe a notícia da necessidade da internação da criança é preciso que a mesma se reorganize para poder cuidá-la nesse contexto. No hospital, a família permanece em interação com a criança. Ao assumir a responsabilidade pelo seu cuidado procura adaptar-se ao hospital e organizar-se para cuidar adotando diversas estratégias. Nesse sentido, a hospitalização envolve a necessidade de profunda adaptação, impondo aos familiares novas formas de organização(18).

A fim de adaptar-se ao mundo do hospital e organizar-se melhor para cuidar, a família busca informações acerca do tratamento fornecido à criança no hospital. Neste sentido, a informação é a principal ajuda que os profissionais da equipe de saúde podem dar às famílias. Estas informações devem ser repetidas tantas vezes quantas forem necessárias, pois, no período de incertezas e ansiedade, nos parece que a família não consegue assimilar todas as informações, de forma imediata. Sendo assim, elas precisam ser claras e objetivas, a fim de facilitar a compreensão da doença. A comunicação e o vínculo entre a família e os profissionais são instrumentos de extrema importância, pois ajudam os familiares a compreender melhor o processo de hospitalização e a colaborar com os cuidados $^{(19)}$. 
A família acostumada a cuidar da criança, procura reproduzir no hospital os cuidados domiciliares, tentando, assim, manter suas crenças, costumes e padrões de vida. A presença de um familiar junto à criança faz com que ela se sinta segura, cuidada, animada, acomodada, descansada, mais confiante, alegre, amada e protegida melhorando sua adaptação ao hospital e ao tratamento ${ }^{(20)}$.

No entanto, em algumas situações, a família não consegue reproduzir no hospital os mesmos cuidados que realiza no domicílio. Os conhecimentos em relação às práticas de cuidado que o familiar cuidador adquiriu na própria família, nas suas tradições, cultura e vivência não dão conta das novas necessidades de cuidado apresentadas pela criança no hospital. Desta forma, novas interações terão que ocorrer, de forma que este familiar cuidador incorpore novos referenciais que 0 habilite ao cuidado ${ }^{(21)}$.

Estas interações se dão na espacialidade das enfermarias, corredores, posto de enfermagem e em outros locais do hospital, no qual as famílias cuidam da criança ao vivenciar sua internação. Apesar de provisório, principalmente a enfermaria, precisa ser organizada, de forma a facilitar o cuidado. Este espaço simbolicamente representa a moradia da família no hospital. É onde se concretiza o ser família, através das suas interações. A este ambiente, a família procura imprimir certa familiaridade, organizando-o de forma a reconhecê-lo como o seu espaço ${ }^{(21)}$.

Desta forma, mesmo que a enfermaria seja coletiva e não possua limites visíveis de espaço físico, passa a ser organizada para que cada família reconheça a sua identidade, estabeleça uma territorialidade, exercendo ali sua singularidade, além de ser o local onde ela pode exercitar certa privacidade. Neste local, o familiar cuidador no hospital precisa produzir uma nova organização, na busca por apoio. Este se concretiza na forma de interações com outras pessoas, objetos e consigo mesma, no sentido de atender às demandas geradas pelo cuidado hospitalar à criança ${ }^{(7)}$.

No momento que a criança interna, o familiar vai se apropriando da cultura hospitalar, adquirindo conhecimentos acerca das condições da criança, normas de funcionamento da instituição, identificação e hierarquia dos membros da equipe de saúde, na tentativa de proporcionar o melhor para a criança e organizar o ambiente do cuidado ${ }^{(22)}$. Assim, ao vivenciar a internação hospitalar da criança, a família passa a conviver com a tecnologia ali existente, precisando familiarizar-se com ela. Geralmente, os profissionais desviam o foco principal de atenção, que deveria ser a criança e sua família, para as práticas tecnicistas e os equipamentos sofisticados ao seu redor. Dessa forma, a equipe tem o seu enfoque voltado para a tecnologia da unidade tornando o cuidado despersonalizado e pouco acolhedor ${ }^{(23)}$.

Nesta perspectiva, em diversas situações lutam pelos seus direitos e sugerem melhorias, com vistas a facilitar os cuidados à criança no hospital. Utilizam como estratégias de cuidado à criança o reclamar, o questionar, o negar-se, o brigar, o insistir, o bater o pé e o exigir, exercitando, assim, seu poder e sua resistência frente à equipe de saúde em prol da criança ${ }^{(24)}$.

O cuidado à criança hospitalizada ultrapassa o uso de tecnologia sofisticada e terapêutica medicamentosa, as quais provocam, em geral, sentimentos de ansiedade, medo, estresse e depressão. A presença de familiares durante a internação torna-se uma fonte de proteção, apoio e segurança para criança, tornando o ambiente hospitalar menos agressivo, auxiliando na diminuição do tempo de internação hospitalar ${ }^{(25)}$.

A enfermeira pode fornecer informações e auxílio na instrumentalização da família no hospital, tornando-se fonte efetiva de apoio e suporte a essa, potencializandoa como cuidadora. É fundamental um diálogo claro e aberto entre equipe de saúde e familiares, a fim de amenizar as dúvidas, os medos e as inseguranças presentes na hospitalização. Apesar da sofisticada tecnologia existente no hospital a família consegue incorporar no seu cuidado aspectos afetivos e emocionais de que tanto a criança necessita neste momento.

\section{CONCLUSÃO}

O estudo objetivou conhecer as estratégias utilizadas pela família para cuidar a criança no hospital. A necessidade da internação da criança revela que a família utiliza como estratégias para cuidá-la buscar informações acerca do tratamento; reproduzir os cuidados domiciliares no hospital; reorganizar o ambiente do cuidado e familiarizar-se com a tecnologia do cuidado.

A internação da criança no hospital altera a dinâmica familiar, levando à necessidade de adaptação à situação vivida. Nesse contexto, a família precisa aprender um novo modo de cuidar para atender as demandas específicas de cuidado da criança, necessitando do apoio dos profissionais da enfermagem. Esses precisam ouvila, percebendo a sua problemática, suas perspectivas, as relações que existem entre seus membros e o mundo social no qual se inserem, refletindo a respeito de suas 
necessidades e capacidade para cuidar, compartilhando com ela o cuidado à criança.

Ao implementar estratégias de cuidado à criança a família torna-se copartícipe do seu processo de internação, exercendo sua autonomia, sentindo-se importante e produtiva, amenizando os efeitos negativos da hospitalização para a criança. Conhecer as estratégias do familiar no cuidado a crianças no hospital torna-se importante para subsidiar a prática da enfermagem junto a essas famílias e crianças. A partir desse conhecimento o enfermeiro poderá planejar formas de instrumentalizar a família para o cuidado, tornando o ambiente hospitalar humanizado, propiciando à criança um cuidado qualificado e sensível.

O cuidado familiar à criança no hospital é complexo, exigindo dedicação e apoio. É um cuidado singular construído no dia a dia da internação e prestado de acordo com as necessidades cotidiana da criança. Apresenta-se o hospital como local privilegiado para o cuidado familiar, merecendo um olhar diferenciado dos profissionais da saúde.

Assim, a atuação da enfermagem deve ser também, voltada à família de forma que a mesma adquira

\section{REFERÊNCIAS}

1. Lee WS, Chai PF, Ismail Z. Impact on parents during hospitalization for acute diarrhoea in young children. Singapore Med J. 2012;53(11):755-9.

2. Sousa LD, Gomes GC, Silva MRS, Santos CP, Silva BT. A família na unidade de pediatria: percepções da equipe de enfermagem acerca da dimensão cuidadora. Cienc Enferm. 2011;17(2): 87-95.

3. Gomes ILV, Caetano R, Jorge MSB. Conhecimento dos profissionais de saúde sobre os direitos da criança hospitalizada: um estudo exploratório. Ciênc Saúde Coletiva 2010; 15(2): 46370.

4. Gomes GC, Oliveira PK. Vivências da família no hospital durante a internação da criança. Rev Gaúcha Enferm. 2012;33(4):165-171.

5. Quirino DD, Collet N, Neves AFGB. Hospitalização infantil: concepções da enfermagem acerca da mãe acompanhante. Rev Gaúcha Enferm. 2010;31(2):300-6.

6. Kuo DZ, Houtrow AJ, Arango P, Kuhlthau KA, Simmons JM, Neff JM. Family-centered care: current applications and future directions in pediatric health care. Id Health J. 2012; 16(2): 297305.

7. Gomes GC, Pintanel AC, Strasburg AC, Erdmann AL. O apoio social ao familiar cuidador durante a internação hospitalar da criança. Rev Enferm UERJ. 2011;19(1):64-9.

8. Gomes GC, Erdman AL, Busanello J. Refletindo sobre a inserção da família no cuidado à criança hospitalizada. Rev Enferm UERJ. 2010;18(1):143-47.

9. Simon TD, Berry J, Feudtner C, Stone BL, Sheng X, Bratton $\mathrm{SL}$, et al. Children with complex chronic conditions in inpatient hospital settings in the United States. Pediatrics.

2010;126(4):647-55.

10. Romaniuk D, O'Mara L, Akhtar-Danesh N. Are parents doing what they want to do? Congruency between parents' actual and desired participation in the care of their hospitalized child. Issues Compr Pediatr Nurs. 2014:1-19. equilíbrio e qualidade de vida, mesmo no contexto da doença e da hospitalização da criança. O enfermeiro deve ser capaz de desenvolver um processo educativo adequado às reais necessidades da criança e da família, mediando os saberes necessários ao cuidado familiar à criança no hospital. Atuar junto à família pode ser fonte segura de suporte para que a mesma consiga fortalecerse para o cuidar, adquirindo habilidades e competências necessárias para o enfrentamento positivo da hospitalização da criança de forma a implementar estratégias efetivas para o seu cuidado.

Conhecer a dimensão cuidadora da família à criança no hospital mostra que a família, mesmo não estando no seu ambiente de conforto, não abdica do seu papel de cuidadora da criança. Auxiliá-la neste desempenho coloca a enfermagem como parceira, fortalecendo a família como unidade social de cuidado a seus membros e a unidade de pediatria como palco do processo educativo em e para a saúde. Esta forma de cuidar pode tornar o hospital reconhecido, não apenas como local de doença, dor e sofrimento, mas, também, palco de aprendizagem, promoção de saúde e prevenção de doenças.

11. Higham S, Davies R. Fathers' roles when their child is in hospital. Nurs Times. 2013; 109(35):26-7.

12. Wegner W, Pedro, ENR. Safety in care circumstances: prevention of adverse events in the hospitalization of children. Rev Lat Am Enfermagem. 2012; 20(3):427-34.

13. Pimenta EAG, Collet N. Dimensão cuidadora da enfermagem e da família na assistência à criança hospitalizada: concepções da enfermagem. Rev Esc Enferm USP. 2009;43(3):622-29 .

14. Lee RL, Lau VW. An interpretive phenomenological study of chinese mothers' experiences of constant vigilance in caring for a hospitalized sick child. J Adv Nurs. 2013;69(8):1808-18. 15. Mendes MGSR, Martins MMFPS. Parceria nos cuidados de enfermagem em pediatria: do discurso à ação dos enfermeiros. Rev Enf Ref. 2012;III(6):113-21.

16. Glaser BG, Strauss AL. The discovery of grounded theory. New York: Aldine; 1967.

17. Strauss A, Corbin, J. Pesquisa qualitativa: técnicas e procedimentos para o desenvolvimento da teoria fundamentada. Porto Alegre: Artmed; 2008.

18. Grau C, Hawrylak F.M. Family and chronic paediatric illness. An Sist Sanit Navar. 2010;33(2):203-12.

18. Costa JB, Mombelli MA, Marcon SS. Avaliação do sofrimento psíquico da mãe acompanhante em alojamento conjunto pediátrico. Estud Psicol. (Campinas). 2009; 26(3):317-25. 19. Melo WA, Marcon SS, Uchimura TT. A hospitalização de crianças na perspectiva de seus acompanhantes. Ver Enferm UERJ. 2010;18(4):565-71.

20. Molina RCM, Fonseca EL, Waidman MAP, Marcon SS. A percepção da família sobre sua presença em uma Unidade de Terapia Intensiva Pediátrica e Neonatal. Rev Esc Enferm USP. 2009;43(3):630-38.

21. Sumanović-Glamuzina D, Sesar I, Krišto B, Ostojić L. Childand family- centered care in the treatment of children knowledge, attitudes, practice. Psychiatr Danub. 2013;25 Suppl $1: 37-40$.

22. Souza TV, Oliveira ICS. Interação familiar/acompanhante e equipe de enfermagem no cuidado à criança hospitalizada: 
perspectivas para a enfermagem pediátrica. Esc Anna Nery Rev Enferm. 2010;14(3):551-9.

23. Silva LJ, Silva LR, Christoffel MM. Tecnologia e humanização

na Unidade de Terapia Intensiva Neonatal: reflexões no contexto

do processo saúde-doença. Rev Esc Enferm USP. 2009;43(3):

684-89.

24. Xavier DM, Gomes GC, Barlem ELD, Erdmann AL. A família revelando-se como um ser de direitos durante a internação hospitalar da criança. Rev Bras Enferm. 2013; 66(6): 866-72.

25. Facio BC, Matsuda LM, Higarashi IH. Internação conjunta pediátrica: compreendendo a negociação enfermeiro-

acompanhante. REE. 2013;15(2):447-53.

Artigo recebido em 10/11/2012.

Aprovado para publicação em 12/11/2013.

Artigo publicado em 30/06/2014. 